\title{
EFFECTS OF A NON-STEROIDAL ANTI-INFLAMMATORY DRUG ON DELAYED ONSET MUSCLE SORENESS AND INDICES OF DAMAGE
}

\author{
A. E. DONNELLY*, K. McCORMICK $\ddagger$ R. J. MAUGHAN*, P. H. WHITING† and P. M. CLARKSON $¥$ \\ *Department of Environmental \& Occupational Medicine and tDepartment of Chemical Pathology, University Medical School, Aberdeen, Scotland \\ ¥Department of Exercise Science, University of Massachusetts, Amherst, MA 01003, USA
}

\begin{abstract}
Twenty untrained male volunteers were required to run downhill for $\mathbf{4 5}$ minutes on a motor driven treadmill to induce muscle soreness. The volunteers took diclofenac or placebo before and for 72 hours after two runs 10 weeks apart, in a randomised double blind crossover design. Subjective soreness was assessed before and at intervals up to 72 hours after each run; venous blood samples, collected at the same time intervals, were used to estimate serum activities of creatine kinase, lactate dehydrogenase and aspartate aminotransferase and serum concentrations of creatinine and urea. Subjective soreness and the biochemical parameters increased after both runs, although the serum enzyme response to the second run was reduced. Diclofenac had no influence on the serum biochemical response to downhill running. Although overall soreness was not affected by diclofenac, individual soreness measurements were reduced by diclofenac at the first period of the study. These results suggest that diclofenac does not influence muscle damage, but may slightly reduce the associated soreness.
\end{abstract}

Key words: Diclofenac, Downhill running, Muscle damage, Muscle soreness, Serum enzymes

\section{INTRODUCTION}

Delayed onset muscle soreness has been experienced by most individuals but its symptoms, soreness which peaks at 24-48 hours after exercise and muscle weakness (Newham et al, 1983) are tolerated rather than treated, since no effective remedy is known. Increases in serum activities of the enzymes creatine kinase (CK), lactate dehydrogenase (LDH) and aspartate aminotransferase (AST) associated with the perceived soreness are believed to be a result of fibre damage involving increased membrane permeability (Schwane et al, 1983; Norregaard Hansen et al, 1982).

There is evidence for an inflammatory-type response in exercise damaged muscle. Infiltration of macrophages has been detected in the exercise-damaged muscles of mice (Salminen, 1985) and the number of these cells peaks at 2472 hours post exercise, decreasing thereafter. This increase in the number of macrophages has been seen to follow the same time course as an increase in lysosomal activity (Salminen, 1985). Macrophage infiltration of muscle has been observed in humans with the same time course after running (Hikida et al, 1983). However, after eccentric exercise of either the calf or biceps, peak infiltration occurred at 12 days post-exercise, much later than that reported in mice (Jones et al, 1985).

Previous attempts to treat delayed onset muscle soreness include the use of the synthetic hydrocortisone analogue, prednisolone, which is an anti-inflammatory agent. This has been shown to reduce CK efflux in dogs after treadmill running (Wagner and Critz, 1968) but did not affect CK efflux or soreness perception in humans following a stepping exercise (Headley et al, 1986). Also in humans, an attempt to reduce perceived soreness after eccentric exercise using the cyclo-oxygenase inhibitor flurbiprofen produced no measurable effect (Kuipers et al, 1985). Recently, Salminen and Kihlstrom (1987) demonstrated that indomethacin, a non-steroidal anti-inflammatory drug, reduced inflammation and histological changes in the muscles of mice following exercise. The only evidence for the effectiveness of anti-inflammatory drugs in delayed

Address for correspondence:

Dr. R. J. Maughan

Department of Environmental \& Occupational Medicine

University Medical School

Foresterhill

Aberdeen AB9 2ZD onset muscle soreness in humans is that of Bansil and coworkers in which aspirin reduced soreness and preverited changes in prostaglandin E and F2 alpha levels observed in a control group (Bansil et al, 1985).

The histological evidence seems to show the occurrence of an inflammatory-type response, a conclusion which is supported by the action of aspirin and indomethacin but not by the results of the trial using flurbiprofen. The object of this study was to examine the effects of the antiinflammatory drug diclofenac on perceived soreness and enzyme release by use of a double blind crossover trial.

\section{METHODS}

Twenty healthy untrained male subjects in the age range 18-30 years (20 \pm 1 , mean $\pm S E)$ participated in this study after completing informed consent documents. Approval for the study was given by the Joint Ethical Committee of Aberdeen University and Grampian Health Board. Each subject performed two periods of $\mathbf{4 5}$ minutes downhill running separated by a 10 -week interval. The subjects received tablets containing either $50 \mathrm{mg}$ diclofenac (Voltarol, Ciba-Geigy Pharmaceuticals) or placebo on each occasion in a double blind crossover according to a previously determined time schedule. One tablet was taken one and a half hours before the run and further tablets were taken at $8 \mathrm{~h}$ intervals up to $72 \mathrm{~h}$ post exercise: the total dose was therefore $500 \mathrm{mg}$. Subjects were required to refrain from strenuous exercise and drinking alcohol during both periods of the study.

Immediately before the first downhill run, the subjects performed a 5 minute run on the level, during which heart rate was monitored by a modified V-lead; running speed was adjusted until a heart rate equivalent to $75 \%$ of age adjusted maximum (220-age) was obtained. Expired air was collected for the last 2 minutes of the run, and expired volume, oxygen consumption and carbon dioxide output were measured by a Gould 9000 IV (Gould Electronics Ltd., Coventry, UK) automated gas analysis system.

The ECG leads were then removed and the subjects ran at the same speed down a slope of $12^{\circ}$ for 45 minutes. Ten weeks later each subject completed a second 5 minute level and 45 minute downhill run at the same speed as before. Expired air was collected from the 19th to $21 \mathrm{st}$ minute and from the 39th to 41 st minute of each run. 
Blood samples were collected immediately before, immediately after and at $6 \mathrm{~h}, 24 \mathrm{~h}, 48 \mathrm{~h}$ and $72 \mathrm{~h}$ after completion of each run. The blood was allowed to clot at room temperature before centrifugation to obtain serum which was stored at $-20^{\circ} \mathrm{C}$ until analysis. Total CK activity was estimated at $37^{\circ} \mathrm{C}$ using an RA 1000 random access analyser (Technicon Ltd., Basingstoke, UK) with a Technicon test kit. Activities of LDH and AST were measured using a SMAC autoanalyser (Technicon Ltd., Basingstoke, UK) along with other serum biochemical parameters including creatinine and urea concentration.

Perceived muscle soreness was evaluated by use of a questionnaire immediately before, immediately after and at $6 \mathrm{~h}, 24 \mathrm{~h}, 48 \mathrm{~h}$ and $72 \mathrm{~h}$ after completion of each run. Subjects were asked to rate their general soreness on a scale of 1 (normal) to 10 (very, very, sore) for the following areas; front thigh, back thigh, buttocks, front lower leg and back lower leg. In addition, muscle soreness was assessed at three specific sites in each area using a metal probe. One site was in the middle, the other 2 sites were at either end of the muscle. Additional ratings of general soreness were made for abdomen, shoulders and arms. A pressure of $62,400 \mathrm{Nm}^{-2}$ (19.6 $\mathrm{N}$ over $\left.3.14 \mathrm{~cm}^{2}\right)$ was delivered to each site by a flat-ended metal probe with a calibrated spring mechanism. Soreness elicited by this pressure was recorded using the same scale as before. The 23 soreness values on each questionnaire sheet were summed to provide a figure for total soreness at each timepoint. This was analysed in addition to the individual soreness measurements.

Repeated measures analysis of variance was used to identify treatment period and time effects for each measurement. All values in the text, Tables and Figs. refer to mean \pm SEM.

\section{RESULTS}

The speed at which the volunteers ran downhill was $2.53 \pm 0.17$ m.s ${ }^{-1}$ (range 2.36-2.92 m.s ${ }^{-1}$ ). Oxygen consumption during downhill running was significantly less ( $p<0.01$ ) than that measured during the initial run on the flat (Table I). No difference in oxygen uptake was observed between the two downhill runs.

\section{TABLE I}

Body weight and oxygen consumption $\left(\mathrm{VO}_{2}\right)$ in the first and second downhil runs. Values for running downhill were significantly lower than those recorded during running on the level $(P<0.01)$

\begin{tabular}{lll}
\hline & First run & Second run \\
\hline Body weight (kg) & $67.9 \pm 1.1$ & $67.9 \pm 1.1$ \\
$\mathrm{VO}_{2}\left(\mathrm{ml}^{\mathrm{k}} \mathrm{kg}^{-1} \mathrm{~min}^{-1}\right)$ on level & $29.2 \pm 0.7$ & $30.3 \pm 0.7$ \\
$\mathrm{VO}_{2}\left(\mathrm{ml}^{\mathrm{kg}} \mathrm{kg}^{-1} \mathrm{~min}^{-1}\right)$ 19-21 minutes downhill & $22.3 \pm 0.6$ & $23.5 \pm 0.5$ \\
$\mathrm{VO}_{2}\left(\mathrm{ml}^{\mathrm{kg}} \mathrm{kg}^{-1} \mathrm{~min}^{-1}\right)$ 39-41 minutes downhill & $22.1 \pm 0.6$ & $23.8 \pm 0.5$ \\
\hline
\end{tabular}

Elevations in serum CK, LDH, AST, urea and creatinine occurred after both downhill runs. Creatinine, urea and LDH peaked at $6 \mathrm{~h}$ post-exercise, CK and AST at $24 \mathrm{~h}$ postexercise. Soreness peaked at $24 \mathrm{~h}$ following both downhill runs (Tables II and III). When the two periods of the study were compared, it was found that the 3 serum enzymes measured, CK, AST, and LDH, showed a significantly smaller increase after the second downhill run (Fig. 1). The creatinine and urea response to downhill running was the same in both periods of the study (Table III). No differences between diclofenac and placebo groups were detected for any of the serum biochemical parameters measured.
TABLE ॥

Serum biochemical parameters and perceived soreness measurements before and after the first downhill run. All soreness measurements were made on an arbitrary scale of 1-10. All measurements increased significantly over time $(P<0.01)$

\begin{tabular}{|c|c|c|c|c|c|c|}
\hline & Pre & Post & $6 \mathrm{~h}$ & $24 h$ & $48 h$ & $72 \mathrm{~h}$ \\
\hline $\begin{array}{l}\text { CK } \\
\left(I U . I^{-1}\right)\end{array}$ & $66 \pm 8$ & $88 \pm 15$ & $220 \pm 26$ & $220 \pm 39$ & $149 \pm 33$ & $150 \pm 34$ \\
\hline $\begin{array}{l}\text { LDH } \\
\left(\text { IU. }\left.\right|^{-1}\right)\end{array}$ & $160 \pm 7$ & $174 \pm 7$ & $177 \pm 6$ & $166 \pm 7$ & $158 \pm 6$ & $160 \pm 6$ \\
\hline $\begin{array}{l}\text { AST } \\
\left(I U . I^{-1}\right)\end{array}$ & $20 \pm 1$ & $20 \pm 1$ & $20 \pm 2$ & $31 \pm 3$ & $26 \pm 2$ & $26 \pm 3$ \\
\hline $\begin{array}{l}\text { Creatinine } \\
\text { (umol.1-1) }\end{array}$ & $88 \pm 4$ & $93 \pm 5$ & $96 \pm 5$ & $93 \pm 5$ & $91 \pm 5$ & $90 \pm 5$ \\
\hline $\begin{array}{l}\text { Urea } \\
\left.\text { (mmol. }\left.\right|^{-1}\right)\end{array}$ & $4.5 \pm 0.2$ & $4.7 \pm 0.2$ & $5.3 \pm 0.3$ & $5.0 \pm 0.2$ & $4.5 \pm 0.3$ & $4.5 \pm 0.3$ \\
\hline $\begin{array}{l}\text { Total } \\
\text { Soreness }\end{array}$ & $23 \pm 0$ & $32 \pm 2$ & $44 \pm 3$ & $42 \pm 4$ & $39 \pm 1$ & $29 \pm 1$ \\
\hline $\begin{array}{l}\text { Soreness } \\
\text { in the front } \\
\text { lower leg }\end{array}$ & $1.1 \pm 0.1$ & $1.7 \pm 0.2$ & $1.7 \pm 0.2$ & $2.5 \pm 0.3$ & $1.8 \pm 0.2$ & $1.5 \pm 0.1$ \\
\hline
\end{tabular}

\section{TABLE III}

Serum biochemical parameters and perceived soreness measurements before and after the second downhill run. All soreness measurements were made on an arbitrary scale of 1-10. All measurements increased significantly over time $(P<0.01)$

\begin{tabular}{|c|c|c|c|c|c|c|}
\hline & Pre & Post & $6 \mathrm{~h}$ & $24 \mathrm{~h}$ & $48 h$ & $72 \mathrm{~h}$ \\
\hline $\begin{array}{l}\text { CK* } \\
\left(I U . I^{-1}\right)\end{array}$ & $52 \pm 4$ & $61 \pm 5$ & $118 \pm 9$ & $117 \pm 17$ & $81 \pm 16$ & $75 \pm 14$ \\
\hline $\begin{array}{l}\text { LDH }^{* *} \\
\left(I U .1^{-1}\right)\end{array}$ & $148 \pm 8$ & $165 \pm 8$ & $157 \pm 9$ & $149 \pm 9$ & $143 \pm 7$ & $144 \pm 8$ \\
\hline $\begin{array}{l}\text { ASTt } \\
\left.\text { (IU. } I^{-1}\right)\end{array}$ & $18 \pm 1$ & $20 \pm 1$ & $22 \pm 1$ & $23 \pm 1$ & $21 \pm 2$ & $20 \pm 2$ \\
\hline $\begin{array}{l}\text { Creatinine } \\
\text { (umol. }^{-1} \text { ) }\end{array}$ & $91 \pm 2$ & $96 \pm 2$ & $103 \pm 4$ & $94 \pm 3$ & $93 \pm 3$ & $93 \pm 3$ \\
\hline $\begin{array}{l}\text { Urea } \\
\text { (mmol.1-1) }\end{array}$ & $4.8 \pm 0.2$ & $5.0 \pm 0.2$ & $5.6 \pm 0.3$ & $5.2 \pm 0.2$ & $4.8 \pm 0.2$ & $4.7 \pm 0.2$ \\
\hline $\begin{array}{l}\text { Total } \\
\text { Soreness }\end{array}$ & $23 \pm 0$ & $31 \pm 2$ & $29 \pm 2$ & $35 \pm 3$ & $32 \pm 2$ & $29 \pm 2$ \\
\hline $\begin{array}{l}\text { Total } \\
\text { soreness } \\
\text { in the front } \\
\text { lower leg }\end{array}$ & 1.0 & $1.3 \pm 0.1$ & $1.2 \pm 0.1$ & $1.5 \pm 0.2$ & $1.4 \pm 0.2$ & $1.2 \pm 0.1$ \\
\hline
\end{tabular}

Reductions from 1st period of study:

$\begin{array}{ll}* F_{1,18}=7.53, p<0.05 & * * F_{1,18}=6.08, p<0.05 \\ +F_{1,18}=5.64, p<0.05 & \neq F_{1,18}=10.54, p<0.01\end{array}$

The response of total soreness did not differ significantly between the two periods of the study (Fig. 2). One individual soreness measurement, soreness in the front of the lower leg did show a reduced response at the second period of the study $\left(F_{1,18}=10.58, p<0.01\right.$, Tables II and III). Administration of diclofenac did not significantly reduce total soreness at either period of the study, nor did it consistently affect any of the individual soreness measurements. It did, however, produce a reduction of some individual soreness measurements at the first period of the study. These were general soreness in the front lower leg $\left(F_{1,18}=4.54, p<0.05\right)$ and back thigh $\left(F_{1,18}=4.40, p<0.05\right)$ and probe-induced soreness in the middle of the back thigh $\left(F_{1,18}=6.52\right.$, $\mathrm{p}<0.05)$.

A significant (period $\times$ treatment) interaction was detected for two of the individual soreness measurements, soreness in the front lower leg $\left(F_{1,18}=7.73, p<0.05\right)$ and 

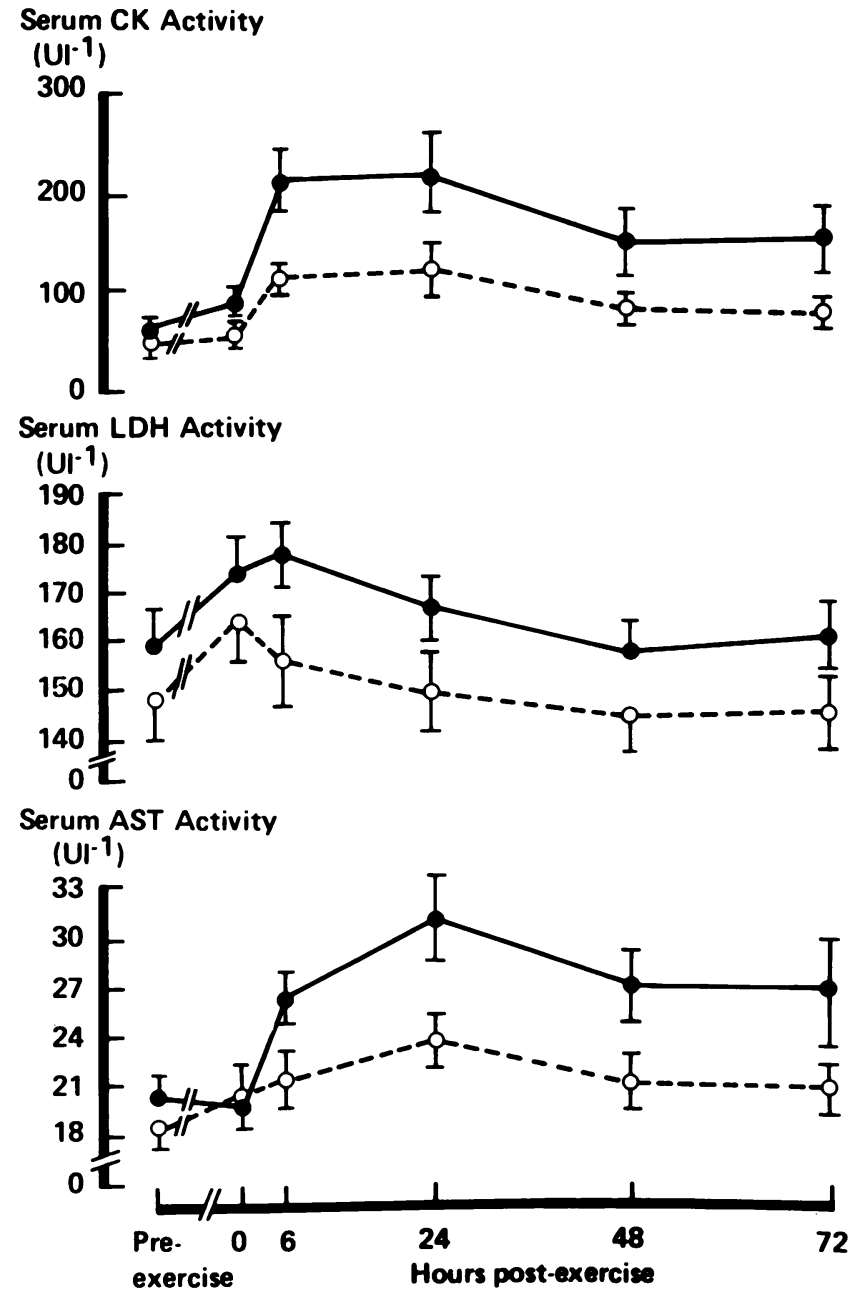

Fig. 1: Activity of enzymes in the serum (Mean \pm SEM)

- First period of study

- Second period of study

All 3 enzymes demonstrated a significantly lower increase over time at the second period. ( $p<0.05$, repeated measures ANOVA)

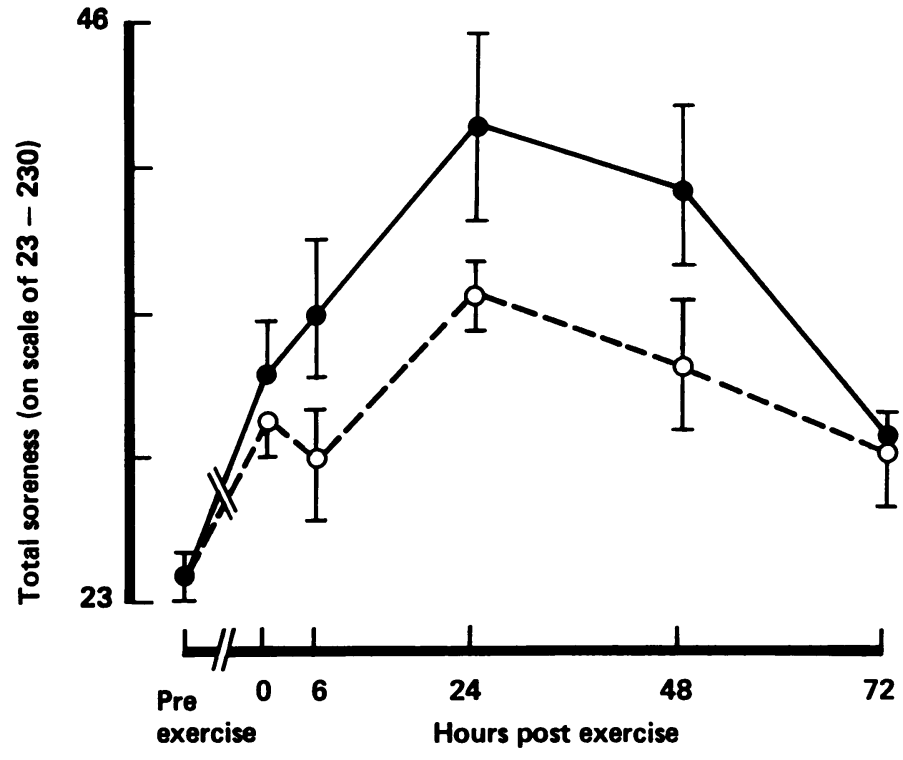

Fig. 2: Total soreness at the first and second periods of the study (Mean \pm SEM)

- First period of study

O- Second period of study

The two curves do not differ significantly soreness induced by probing in the middle region of the back thigh $\left(F_{1,18}=4.42, p<0.05\right)$. The latter measurement was reduced in the diclofenac group at the first period of the study, but at the second period, soreness was lower in the placebo group (Fig. 3).
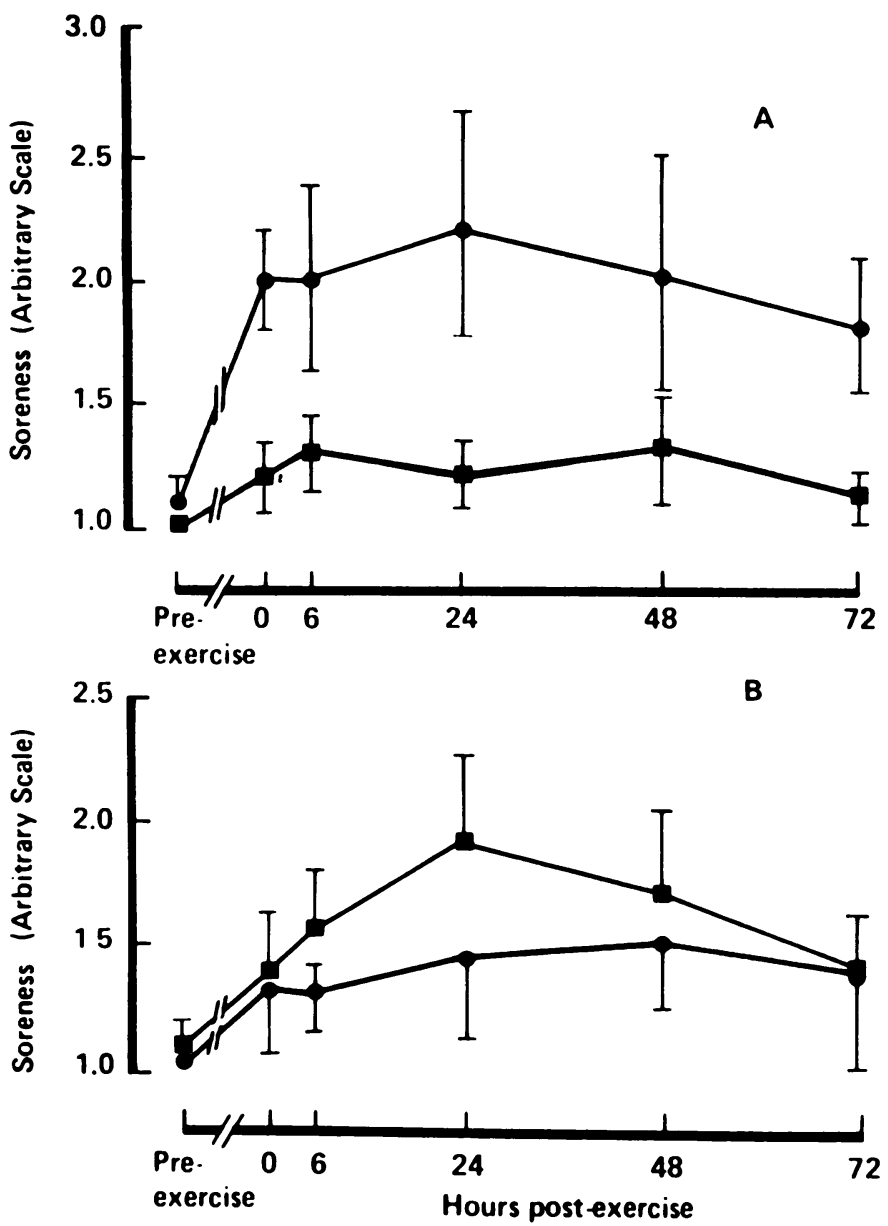

Fig. 3: Soreness in the middle of the back thigh at the first (upper) and second (lower) periods of the study (Mean \pm SEM)

-Diclofenac group

- Placebo group

A significant treatment $x$ period interaction was detected for this measurement ( $p<0.05$, repeated measures ANOVA)

\section{DISCUSSION}

Negative work is energetically less costly than positive work (Asmussen, 1953; Schwane et al, 1983), so it is unremarkable to find in this study that oxygen consumption in downhill running was less than that for the same speed on the level. In spite of this diminished energy cost, however, more muscle damage occurs following eccentric exercise than concentric exercise (Asmussen, 1956).

The reduction in size of the enzyme response to exercise in the second period of the study has been seen before, both in rats (Schwane and Armstrong, 1983) and in humans (Byrnes et al, 1985; Jones and Newham, 1985; Kuipers et al, 1985). This reduction in response cannot be attributed to a change in aerobic metabolism, since no difference in oxygen consumption was observed between the two downhill runs. In this study it is evident that a single bout of 45 minutes downhill running is sufficient to produce a protective effect lasting at least 10 weeks which reduces muscle enzyme release after a second bout of eccentric exercise. Such an effect has been seen up to 6 weeks after an initial downhill run (Byrnes et al, 1985), but a second downhill run at 9 weeks after the first produced the same 
magnitude of response as the first. The mechanism by which this "repeated bout effect" operates is not yet understood (Byrnes and Clarkson, 1986).

It is of interest that serum creatinine and urea concentrations were elevated after the two runs. Similar increases in creatinine and urea have been observed during a military training course (Ross et al, 1983) and following a ski race (Refsum and Stromme, 1974). These increases may be due to a change in the pattern of excretion, but in view of the short duration and relatively low intensity of the exercise it seems more probable that the high levels recorded are related to muscle damage. Creatinine is found in high levels in muscle cells, so it may leak into the serum after muscle damage. The increase in serum urea may indicate an increase in protein catabolism. An increase in the excretion of 3-methylhistidine and urea has been noted after exercise in rats and humans, indicating that muscle protein breakdown occurred during or after exercise (Dohm et al, 1982).

In contrast to the decreased elevations of the muscle enzymes at the second period, serum creatinine and urea showed similar elevations following both downhill runs. This could indicate that neither serum parameter is related to muscle damage, or it could mean that the "repeated bout effect" does not reduce creatinine leakage or protein turnover.

The time course of release of CK and other serum enzymes following exercise in this study is similar to that seen in other studies using downhill running as the exercise model (Schwane et al, 1983). This short time course of release contrasts sharply with the maximum CK being recorded at 5 or more days post-exercise in studies by Newham, Jones and co-workers (Newham et al, 1983; Jones and Newham, 1985; Jones et al, 1985). There is however, an important difference between those reports and the present study, i.e. the magnitude of enzyme release involved. Exercise protocols used by Newham, Jones and co-workers resulted in extreme elevations in CK, up to 100 times the level seen in the present study. This would indicate that the muscle damage produced in the present study was far less severe. The time course and magnitude of enzyme elevation in the present study is similar to that observed by Mayer and Clarkson (1984) after isometric exercise.

Diclofenac would appear to have no effect on exerciseinduced muscle damage, assuming that this can be inferred from the release of muscle proteins into the blood, nor did it reduce overall muscle soreness. The differing action of diclofenac in reducing soreness in the front lower leg and other regions is difficult to explain. It is not clear why diclofenac should reduce soreness at the first period of the study but have no effect or an opposite effect at the second. One possibility is that some form of interaction occurs between the action of diclofenac and the "repeated bout effect". Such an interaction could occur in the group receiving diclofenac at the first period of the study. Diclofenac may directly or indirectly influence the muscle so that the protective effect against a second bout is enhanced. in a recent review, Evans (1987) suggested that such an interaction may occur when non-steroidal antiinflammatory drugs are used to relieve muscle soreness. His reasoning was that since prostaglandins increased muscle protein synthesis, inhibiting their production would prevent or slow muscle repair, making the muscle susceptible to further damage. The interaction detected here seemed to work in the opposite direction, however, actually protecting against further soreness (though not damage).

In conclusion, it would seem that diclofenac does not reduce serum enzyme changes but may have some action in reducing soreness at specific points.

\section{ACKNOWLEDGEMENTS}

This study was supported by Ciba-Geigy Pharmaceuticals. A. E. Donnelly is supported by a University of Aberdeen Medical Endowments Research Studentship, and R. J. Maughan is supported by a grant from Shell Expro (UK) Ltd. K. McCormick's visit to the department was funded by the Health Promotion Research Trust.

\section{References}

Asmussen, E., 1953 "Positive and negative muscular work". Acta Physiol. Scand. 28: 364-382.

Asmussen, E., 1956 "Observations on experimental muscle soreness". Acta Rheum.Scand. 2: 109-116.

Bansil, C. K., Wilson, G. D. and Stone, N. H., 1985 “Role of prostaglandins $E$ and $F_{2}$ alpha in exercise induced delayed muscle soreness". Med.Sci. Sports Exerc. 17: 276.

Byrnes, E. C., Clarkson, P. M., Hsieh, S. S., Frykman, P. N. and Maughan, R. J., 1985 "Delayed onset muscle soreness following repeated bouts of downhill running". J.Appl.Physiol. 59: 710-715.

Byrnes, W. C. and Clarkson, P. M., 1986 “Delayed onset muscle soreness and training". In: Clinics in Sports Medicine, 5, No. 3, pp. 605-613. Ed. Katch, F. I. and Freedson, P. S. W. B. Saunders, Philadelphia.

Dohm, G. L., Williams, R. T., Kasperek, G. J. and VanRij, A. M., 1982 "Increased excretion of urea and N-Methylhistidine by rats and humans after a bout of exercise". J.Appl.Physiol. 52: 27-33.

Evans, W. J., 1987 "Exercise-induced skeletal muscle damage". Phys.Sports Med. 15: 89-100.

Headley, S. A. E., Newham, D. J. and Jones, D. A., 1986 "The effect of prednisolone on exercise induced muscle soreness and damage". Clin.Sci. 70 (Suppl. 13) 85P.

Hikida, R. S., Staron, R. S., Hagerman, F. C., Sherman, W. M. and Costill, D. L., 1983 "Muscle fiber necrosis associated with human marathon runners". J.Neurol.Sci. 59: 185-203.

Jones, D. A. and Newham, D. J., 1985 “The effect of training on muscle pain and damage". J.Physiol. 365: 76P.

Jones, D. A., Newham, D. J., Round, J. N. and Tolfree, S. E. J., 1985 "Experimental human muscle damage; morphological changes in relation to other indices of damage". J.Physiol. 375: 435-44.

Kuipers, H., Keizer, H. A., Vestappen, F. T. J. and Costill D. L., 1985 "The influence of a prostaglandin-inhibiting drug on muscle soreness after eccentric work. Int.J.Sports Med. 6: 336-339.

Mayer, S. J. and Clarkson, P. M., 1984 "Serum creatine kinase levels following isometric exercise". Research Q.Exerc.Sports 55: 191-194.

Newham, D. J., Mills, K. R., Quigley, B. M. and Edwards, R. H. T., 1983 “Pain and fatigue after concentric and eccentric muscle contractions". Clin.Sci. 64: 55-62.

Norregaard-Hansen, K., Bjerre-Knudsen, J., Brodthagen, U., Jordal, R. and Pavlev, P.-E., 1982 "Muscle cell leakage due to long distance training". Eur.J.Appl.Physiol. 48: 177-188.

Refsum, H. E. and Stromme, S. B., 1974 "Urea and creatinine production and excretion in urine during and after prolonged heavy exercise". Scand.J. Clin.Lab.Invest. 33: 247-254.

Ross, J. H., Attwood, E. C., Atkin, G. E. and Villar, R. N., 1983 "A study of the effects of severe repetitive exercie on serum myoglobin, creatine kinase, transaminases and lactate dehydrogenase". Q.J.Med. 206: 268-279.

Salminen, A., 1985 "Lysosomal changes in skeletal muscles during the repair of exercise injuries in muscle fibers". Acta Physiol.Scand.Supplementum 539.

Salminen, A. and Kihlstrom, M., 1987 "Protective effect of indomethacin against exercise-induced injuries in mouse skeletal muscle fibers". Int.J.Sports Med. 8: 46-49.

Schwane, J. A. and Armstrong, R. B., 1983 "Effect of training on skeletal muscle injury from downhill running in rats". J.Appl.Physiol. 55: 969-975.

Schwane, J. A., Johnson, S. R., Vandenakker, C. B. and Armstrong, R. B., 1983 "Delayed onset muscular soreness and plasma CK and LDH activities after downhill running". Med.Sci.Sports Exerc. 15: 151-156.

Wagner, J. A. and Critz, J. B., 1968 "The effect of prednisolone on the serum creatine phosphokinase response to exercise". Proc.Soc.Exp.Biol.Med. 128: 716-720. 